\title{
Assessment of Insulin Resistance and Insulin Growth Factor-1 in Egyptian Patients with Chronic Hepatitis C
}

\author{
Inas Kostandi ${ }^{1}$, Magy Bahgat ${ }^{1}$, Naglaa Zayed ${ }^{2 *}$, Laila Rashed $^{3}$ \\ ${ }^{1}$ Internal Medicine Department, Faculty of Medicine, Cairo University, Cairo, Egypt \\ ${ }^{2}$ Endemic Medicine and Hepatology Department, Faculty of Medicine, Cairo University, Cairo, Egypt \\ ${ }^{3}$ Biochemistry Department, Faculty of Medicine, Cairo University, Cairo, Egypt \\ E-mail:"naglaazayed@yahoo.com \\ Received October 10, 2011; revised November 15, 2011; accepted November 25, 2011
}

\begin{abstract}
Introduction: Insulin resistance (IR) is documented in patients with chronic hepatitis C (CHC), plays an important factor in disease progression and predicting poor response to treatment. In chronic liver disease, levels of insulin-like growth factor-1 (IGF-1) were correlated with IR. Aim: To evaluate IR and serum levels of IGF-1 in Egyptian patients with CHC after anti-viral therapy. Patients and Methods: Forty biopsy-proven, non-diabetic, CHC patients, who received combined IFN/ribavirin therapy, in addition to 10 healthy controls were studied. Serum levels of IGF-1, growth hormone (GH) were measured and HOMA-IR (homeostasis model assessment of IR), body mass index (BMI) were calculated. Baseline data, retrieved from patients' files before initiation of therapy, together with response to antiviral therapy were analyzed with respect to the measured variables. Results: All patients possessed a significant higher HOMA-IR score $(\mathrm{p}=0.02)$, GH levels $(\mathrm{p}<0.001)$ and blood glucose levels $(\mathrm{p}<0.001)$ than controls while significantly lower levels of IGF-1 were found in patients $(\mathrm{p}=0.008)$ with no significant difference between responders and non-responders as regards the previously mentioned variables. HOMA-IR score was significantly correlated with GH levels, $p=0.003$ and with IGF-1 levels in both responders and non responders. Low IGF-1 levels were associated with increase in fibrosis stages and were significantly correlated with insulin $(r=-0.499, p=$ 0.001). Conclusion: CHC patients exhibit an increased HOMA-IR score reflecting the existence of IR irrespective of treatment response. Low IGF-1 levels were associated with advanced stages of fibrosis and thus could contribute to the progression of hepatic fibrosis in $\mathrm{CHC}$.
\end{abstract}

Keywords: Hepatitis C, Insulin Resistance, Interferon, Ribavirin, IGF-1

\section{Introduction}

Hepatitis $\mathrm{C}$ virus (HCV) induced insulin resistance (IR) has been related to steatosis development, fibrosis progression and non-response to interferon (INF)/ribavirin therapy [1]. HCV infected patients showed a higher prevalence of diabetes mellitus (DM) and IR than those infected with hepatitis B [2]. A prospective study of 500 $\mathrm{HCV}$ patients demonstrated a significant correlation between genotype 1 or 4 infection and IR, both in the presence and absence of DM [3]. The mechanism implied in IR is the enhanced production of tumor necrosis factor $\alpha$ (TNF- $\alpha$ ) by the HCV core [4]. Moreover, TNF- $\alpha$ inhibits the function of insulin substrate 1 and 2 and decrease the expression of glucose transporter and lipoprotein lipase in peripheral tissues [5,6]. Increased liver iron accumulation and modification in the levels of adipocytokinemia can have an additional effect on insulin sensitivity in HCV infection [4].

IR can occur early in the course of chronic liver disease [7] independent of body weight, stage of liver disease, and presence or absence of overt DM [8,9]. Moreover, IR is an important predictor of sustained response to antiviral therapy [10], thus improving insulin sensitivity was suggested as a useful adjunct to therapy [11].

Chronic liver disease (CLD) is characterized by acquired growth hormone $(\mathrm{GH})$ resistance, low concentrations of insulin-like growth factor 1 (IGF-1) with respect to normal or elevated GH levels [12]. IR can be induced by high amounts of GH [13] and was correlated with IGF-1 [14]. GH resistance is determined by several factors including malnutrition, impaired liver function, re- 
duced expression of hepatic GH receptors and a possible role of TNF- $\alpha$ in blunting hepatic response to GH in patients with $\mathrm{CHC}^{12}$. IGF-1 was significantly lower in CLD patients due to decreased hepatic production or modified bioavailability secondary to decrease binding proteins [15].

\section{Aim}

Assessment of the IR and serum levels of IGF-1 in Egyptian patients with chronic hepatitis $\mathrm{C}(\mathrm{CHC})$ after treatment with combined IFN/ribavirin therapy.

\section{Patients and Methods}

\subsection{Patients}

Forty non diabetic (fasting blood glucose level less than $6.0 \mathrm{mmol} / \mathrm{litre}$ ), CHC patients, who received combined IFN/ribavirin therapy in the context of a project carried out by the Schistosomal Liver Unit, Cairo University in the period of 2005-2007 and attended at regular follow up, were invited to participate in the study. Patients were enrolled after obtaining an informed consent. They included 32 males and 8 females their age ranged from 2860 years, mean \pm SD: $43.28 \pm 8.25$.

The control group included 10 healthy non diabetic subjects with no history of CLD. They were 3 males and 7 females, mean \pm SD age: $36.60 \pm 9.22$ years with normal liver biochemical profile, negative seromarkers for HBV and HCV and normal abdominal ultrasonography.

Patients with baseline impaired glucose tolerance (diagnosed as blood glucose $\geq 6.1 \mathrm{mmol} / \mathrm{L}$ ), diabetes mellitus and history of alcohol intake were excluded.

All patients and control underwent:

- Full history taking including a nutritional questionnaire concerning dietary restrictions, diet supplementations and weight changes.

- Full clinical examination and BMI was calculated as body weight in kilograms divided by height in $\mathrm{m}^{2}$.

- Recent Investigations: liver functions, kidney functions and complete blood count.

- Sample collection: After an overnight fast, $10 \mathrm{ml}$ of venous blood were withdrawn from each subject in the study then the blood was centrifuged at $3000 \mathrm{rpm}$ for 15 min rapidly after clotting. Serum was separated with Pasteur pipette and divided as aliquots into Ependorff tubes. One tube was used for determination of fasting blood sugar using the available commercials kit. The rest of the Ependorff tubes were kept frozen at $-80^{\circ} \mathrm{C}$ till used for assay of insulin, growth hormone and IGF-1, also this Ependorff was used to detect $\mathrm{HCV}$ infection by reverse transcriptase-poly- merase chain reaction (RT-PCR).

- Fasting blood sugar and fasting serum insulin was determined by radioimmunoassay (RIA) [16].

- IR was calculated by the Homeostasis Model Assessment of Insulin resistance (HOMA-IR), using the following equation: fasting insulin $(\mu \mathrm{U} / \mathrm{ml}) \times$ fasting glucose $(\mathrm{mmol} / \mathrm{L}) / 22.5$ [17].

- Serum IGF-1 and serum GH measured by RIA using reagent purchased from Nichols Institute (San Juan Capistrano, CA) $[18,19]$.

- Recent qualitative RT-PCR for HCV detection was done for patients only. RNA was obtained using the Qiagen extraction protocol (QIAamp Viral RNA Mini kit, Qiagen, Germany) and sensitive in-house nested RT-PCR standardized [20] using primers specific for the 5' noncoding region of the $\mathrm{HCV}$ genome was employed [21].

- Abdominal ultrasound.

Baseline data before the initiation of therapy that was retrieved from their files included:

- History of infection with schistosomiasis, body weight change during treatment and afterwards.

- Type and duration of IFN received: Patients received either recombinant standard IFN $\alpha$-2a 3 million units taken three times per week (22 patients) or $20-\mathrm{kDa}$ linear pegylated (PEG) IFN $\alpha$-2a derived from Hansenula Polymorpha expression system taken once weekly 160 microgram (18 patients) SC, in addition to oral ribavirin taken daily in a dose of $1000-1200$ $\mathrm{mg}$ (according to body weight).

- METAVIR scoring system [22] for assessment of liver biopsy. All of the recruited patients had activity $\leq \mathrm{A} 2$ and $75 \%$ had fibrosis $\leq \mathrm{F} 2$ with minimal or mild steatosis $(<33 \%)$.

- Response to treatment, sustained virological response (SVR) defined as the absence of detectable HCV RNA in serum at the end of treatment and 6 months later was achieved in 10 patients, 18 patients were non responders and 12 relapsers (HCV RNA becomes undetectable on treatment and is detected again after discontinuation of treatment).

\subsection{Statistical Analysis}

Results were expressed as mean \pm standard deviation (SD) or number (\%). Comparison between the mean values of the two groups was done using unpaired student $t$ test while multiple group comparison was performed using ANOVA with post hoc using LSD test. Comparison between categorical data [n (\%)] was done using Chi square test. Correlation between parameters was performed using Spearman's rank correlation coefficient. 
SPSS computer program (version 11 windows) was used for data analysis. p-value less than 0.05 was considered significant; less than 0.01 was considered highly signifycant and less than 0.001 was considered extremely significant.

\section{Results}

All patients expressed a significant higher HOMA-IR score (p-value $=0.02), \mathrm{GH}$ levels $(\mathrm{p}$-value $<0.001)$ and blood glucose levels (p-value $<0.001$ ) than the controls; while mean levels of IGF-1 were significantly lower in CHC patients; p-value $=0.008$ (Table 1). BMI did not show any statistically significant difference between recruited patients and control. Impaired glucose tolerance (blood glucose $\geq 6.1 \mathrm{mmol} / \mathrm{L}$ ) occurred in 9 treated patients, 6 of them were non responders. No dietary restriction or significant weight changes was reported during treatment or in the period afterwards in any of the recruited patients, only mild weight gain was reported by the majority of responders. No significant difference was found on comparing age, sex, BMI, HOMA-IR score, IGF-1, insulin, activity and fibrosis score and steatosis grades between responders and non-responders. Impaired glucose tolerance was noted among non responders com- pared to responders, but with no significant difference. GH levels were significantly different between responders and non-responders, p-value 0.01 (Table 2).

Correlations studies were described as below:

- In control group: HOMA score had a significant positive correlation with both insulin $(\mathrm{r}=0.979$, $\mathrm{p}$-value $=$ $0.01)$ and BMI $(r=0.794, p$-value $<0.01)$, but there was no significant correlation with age, sex, GH levels, IGF-1 levels. Moreover, IGF-1 was not correlated with age, sex, BMI, GH, insulin.

- In all 40 patients (whether responders or non responders), HOMA-IR score was significantly correlated with $\mathrm{GH}$ and insulin levels $(\mathrm{r}=0.451, \mathrm{p}=0.003$, Figure 1), $r=0.852, p=0.01$ respectively. However, age, sex, BMI, IGF-1, stages of fibrosis and achievement of SVR had no significant association with IR.

- HOMA-IR score was significantly correlated with GH $(r=0.566, p=0.001)$ in non responders, and with IGF-1 in non-responders and responders $(\mathrm{r}=-0.381$, $\mathrm{p}=0.038$, Figure 2$)(\mathrm{r}=-0.77, \mathrm{p}=0.009$, Figure 3$)$ respectively.

- IGF-1 was significantly correlated with insulin, $r=$ $-0.499, p=0.001$ (Figure 4), decreased with advanced stages of fibrosis, $r=-0.270, p=0.08$ and had no significant association with age, sex, BMI and GH.

Table 1. Comparison of BMI and laboratory results between CHC patients and controls.

\begin{tabular}{lccc}
\hline \multicolumn{1}{c}{ Variables } & Control $(\mathrm{n}=10)$ & Patients $(\mathrm{n}=40)$ & $\mathrm{p}$-value \\
\hline BMI $<25$ & $25.86 \pm 4.1$ & $28.82 \pm 5.14$ & 0.1 (NS) \\
GH $(5-7 \mathrm{ng} / \mathrm{mL})$ & $7.77 \pm 0.95$ & $12.44 \pm 3.83$ & $<0.001$ \\
IGF-1 $(\mathrm{ng} / \mathrm{mL})$ & $195.12 \pm 6.85$ & $180.45 \pm 16.25$ & 0.008 \\
Serum glucose $(3.9-6.1 \mathrm{mmol} / \mathrm{L})$ & $4.01 \pm 0.32$ & $5.43 \pm 1.30$ & $<0.001$ \\
Insulin $(2-25 \mu \mathrm{IU} / \mathrm{mL})$ & $11.24 \pm 0.95$ & $13.69 \pm 5.86$ & 0.19 (NS) \\
HOMA-IR $(\leq 2.5)$ & $2.01 \pm 0.30$ & $3.45 \pm 1.99$ & 0.028 \\
\hline
\end{tabular}

Values were expressed as mean $\pm \mathrm{SD}$ or number $(\%)$. $\mathrm{p}$-value $\mathrm{NS}=$ not significant, $\mathrm{p}<0.05=$ significant $(\mathrm{S}), \mathrm{p}<0.01=$ highly significant, $\mathrm{p}<0.001=$ extremely significant.

Table 2. Clinical and laboratory data of the studied patients groups.

\begin{tabular}{lccc}
\hline \multicolumn{1}{c}{ Variable } & Responders (10) & Non-responders and relapsers (30) & p-value \\
\hline Age: mean \pm SD & $44.00 \pm 6.91$ & $43.03 \pm 8.75$ & 0.87 (NS) \\
Sex: M/F n (\%) & $9 / 1(90 / 10)$ & $23 / 7(76.7 / 23.3)$ & 0.36 (NS) \\
BMI & $28.05 \pm 4.08$ & $29.07 \pm 5.48$ & 0.88 (NS) \\
GH $(5-7 \mathrm{ng} / \mathrm{mL})$ & $13.92 \pm 2.91$ & $11.95 \pm 4.01$ & $0.01(\mathrm{~S})$ \\
IGF-1 $(\mathrm{ng} / \mathrm{mL})$ & $183.40 \pm 18.83$ & $179.46 \pm 15.52$ & 0.37 (NS) \\
Serum glucose $(3.9-6.1 \mathrm{mmol} / \mathrm{L})$ & $5.43 \pm 1.61$ & $5.42 \pm 1.21$ & 0.79 (NS) \\
Seum glucose $\geq 6.1 \mathrm{mmol} / \mathrm{L}$ & $3(30 \%)$ & $6(20 \%)$ & 0.31 (NS) \\
Insulin $(\mu \mathrm{U} / \mathrm{mL})$ & $14.38 \pm 6.08$ & $13.46 \pm 5.87$ & 0.96 (NS) \\
HOMA-IR $(\leq 2.5)$ & $3.68 \pm 2.23$ & $3.37 \pm 1.94$ & 0.9 (NS) \\
\hline
\end{tabular}

Values were expressed as mean $\pm \mathrm{SD}$ or number (\%). Comparison between the mean values of different parameters was performed using Mann Whitney U test. 


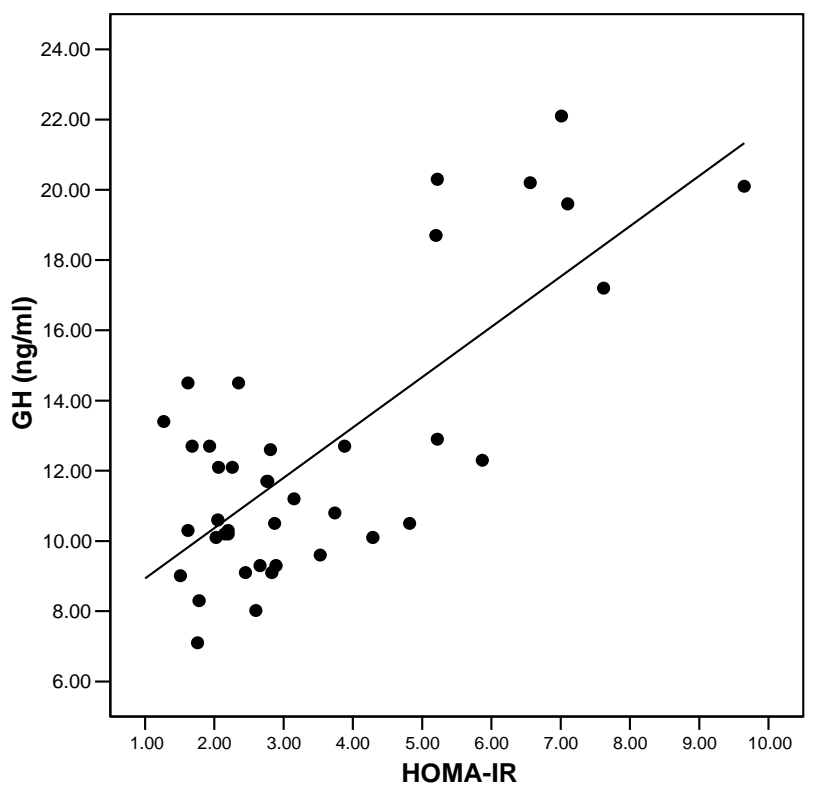

Figure 1. Correlation HOMA-IR and GH $(\mathrm{ng} / \mathrm{ml})$ in all $\mathbf{4 0}$ patients $(r=0.451 ; p=0.003)$.

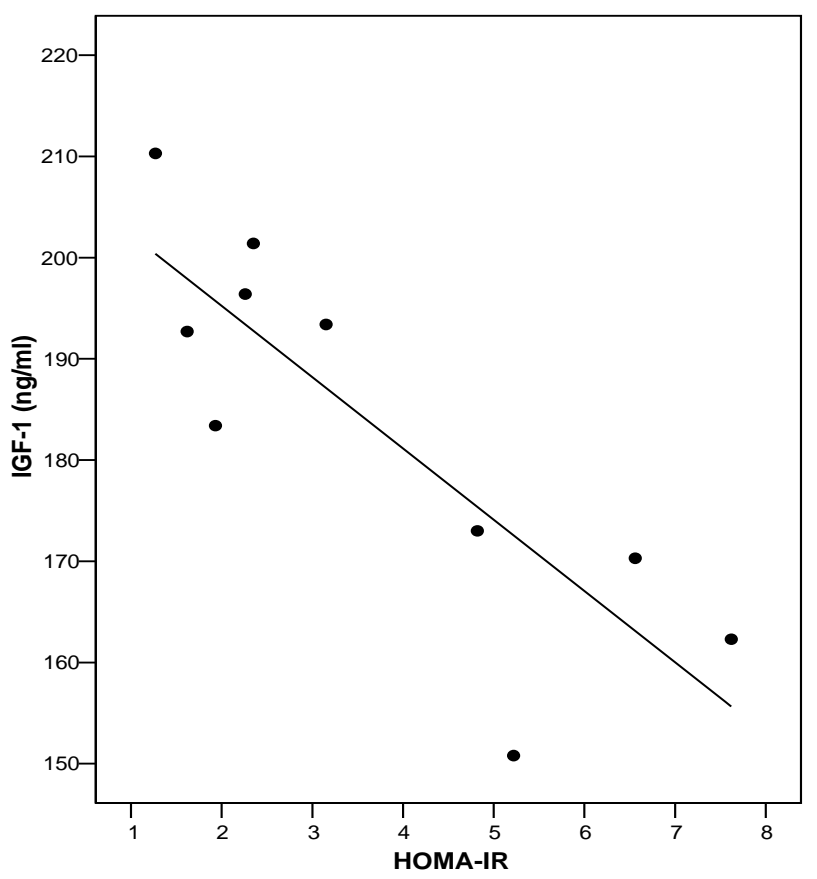

Figure 3. Correlation between HOMA-IR and IGF-1 (ng/ml) in responders group $(r=-0.770 ; p=0.009)$.

- BMI showed a significant positive correlation with the degree of steatosis $(r=0.436, p=0.018)$ which in turn was negatively correlated with the achievement of SVR $(\mathrm{r}=-0.428$, p-value 0.02). Moreover, achievement of SVR was significantly correlated with $\mathrm{GH}$ levels $(\mathrm{r}=$ 0.405 , p-value $=0.009$ ) while age, sex, serum IGF-1 and fibrosis score had no significant association.

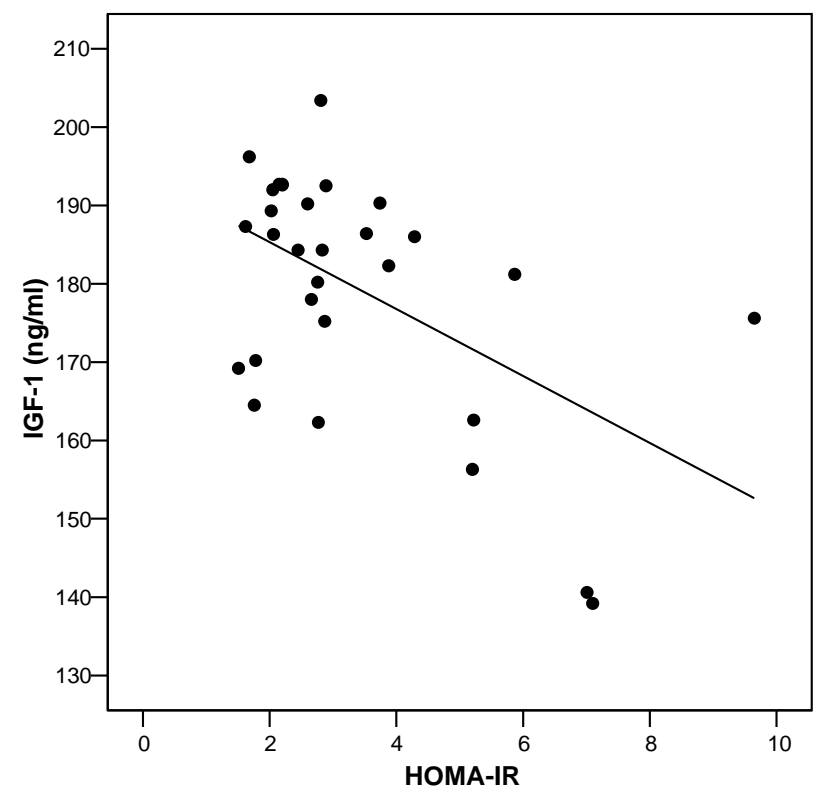

Figure 2. Correlation between HOMA-IR and IGF-1 (ng/ml) in non-responders group $(r=-0.381 ; p=0.038)$.

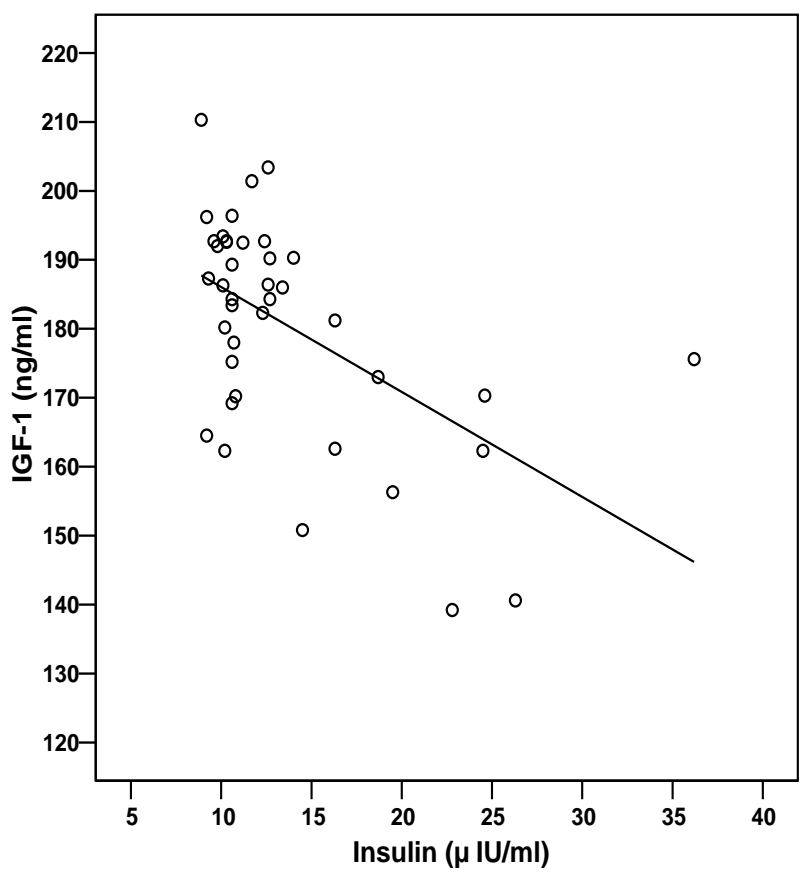

Figure 4. Correlation between IGF-1 and insulin in patients group $(r=-0.499 ; p=0.001)$.

\section{Discussion}

Chronic hepatitis $\mathrm{C}$ has been proposed as a metabolic disease and insulin sensitivity as a predictive factor for liver fibrosis [23]. Increased prevalence of type 2 DM, the development of hepatic steatosis, a more rapid progression of hepatic disease and reduction in the SVR 
have been associated with IR in CHC patient [7].

In the present study, CHC treated patients, whether responders or non-responders, demonstrated significantly higher HOMA-IR and GH levels than healthy controls while levels of IGF-1 were significantly lower. Similarly previous studies reported an HCV induced IR. Moucari et al., reported that IR is a specific feature of HCV genotypes 1 and 4 even in non-diabetic patients and is associated with significant fibrosis that is independent from steatosis [3]. IR may occur at an early stage of liver disease as evidenced by patients with $0-1$ hepatic fibrosis having higher levels of HOMA scores [8]. Hyperinsulinemia, in HCV patients, due to diminished hepatic insulin degradation rate can lead to a false increase of the HOMA-IR [24]. Furthermore, HCV infection by itself can lead to IR as HCV core protein induces hepatic steatosis and interferes with the insulin-signaling pathways [25].

Achieving sustained response depends on several factors such as age, baseline viral load, genotype, fibrosis and baseline glucose concentration [26]. IR is one of the most important host factors in the prediction of response in non diabetic HCV patients and represents a common denominator to the majority of features associated with difficult to treat patients. The risk of developing DM and impaired fasting glucose (IFG) may increase in patients not responding to an antiviral therapy [25].

In the current study, HOMA-IR was not related with the response to antiviral therapy and had no significant difference between responders and non responders. Similar to our results, Mello et al., 2006 [27] reported that IR is related to the abdominal fat and anthropometrical parameters rather than to the antiviral treatment with no changes in the IR observed after therapy. Moreover, the risk of impaired glucose tolerance or DM incidence was not lower between long term responders and non-responders [28].

On the contrary, several data support a relation between IR, sustained response and HCV replication. IR measured by HOMA, decreased in patient with HCV RNA clearance, but not in non-responders and showed a significantly lower HOMA in comparison with baseline IR index [29]. Previous data revealed that hyperinsulinemia can stimulate viral replication and failed to elicit the correlation between viral replication and IR [30].

Most notably, our study demonstrated that BMI, steatosis and fibrosis had no significant association with IR. This may be attributed to the small number of subjects with severe steatosis, mild weight gain reported in the majority of sustained responders, and to the high BMI of the participants compared to other studies. It is worth mentioning that few patients developed impaired fasting glucose tolerance since their last follow up date which could be due to the effect of IFN therapy that might en- hance underlying autoimmunity against beta cells leading to overt type $1 \mathrm{DM}[31,32]$.The lack of correlation between IR and BMI could be due to the other variables affecting IR such as fibrosis stage, steatosis, GH and IGF-1 levels. Moreover, the number of responders in comparison to non-responders also affected the statistical analysis. On the contrary to our results, several investigators have demonstrated that obesity and steatosis were related to IR in chronic $\mathrm{HCV}$ infection $[7,8]$ and that weight loss could improve IR in these patients [33]. Furthermore, the correlation of IR with steatosis severity, BMI [34] could explain the elevated prevalence of impaired fasting glucose [35] and $\mathrm{DM}$ in $\mathrm{CHC}$ patients compared to the general population.

In the present study, there was a lack of correlation between HOMA-IR and fibrosis stages in the recruited patients. The low IGF-1 levels that might reflect severe chronic liver disease were significantly correlated with HOMA-IR in responders and non responders. Previous data illustrated the contribution of IR to the progression of liver fibrosis [8,36-38]. IR was considered a major independent determinant of fibrosis regardless of the genotype and the severity of liver damage [39]. Mean HOMA index increases with the stage of fibrosis [7] and could help to differentiate stages of fibrosis. The presence of steatosis is responsible for causing progressive fibrosis in addition to the role of intrahepatic inflammation $[40,41]$.

In the current study, HOMA-IR score failed to show a significant difference between responders and non-responders. However, both SVR and HOMA-IR were associated with increased GH levels while HOMA-IR was significantly correlated with the low IGF-1 levels. The low IGF-1 levels were negatively correlated with serum insulin, reflected an advanced fibrosis score and were able to display the presence of GH resistance in presence of high GH levels.

Similar to our results, Plöckinger et al., [42] reported high GH levels in treated HCV patients with low IGF-1 concentrations indicating the existence of $\mathrm{GH}$ resistance of hepatocytes and that high amounts of GH can lead to IR [13].These GH levels following therapy may be due to a direct drug effect or related to the suppression of viral load. Furthermore, IGF-1 gene expression was down regulated in progressive chronic liver disease and accordingly serum IGF-1 level decreases [43].

Our results are in general agreement with other studies. Most researchers documented GH resistance in HCV even in the phase preceding cirrhosis [12] as evident by low IGF-1 levels in the presence of normal or increased GH secretion. About $90 \%$ of circulating IGF- 1 originates in the liver. In liver fibrosis, disturbed synthesis of IGF-1 reflects the severity of the clinical stage and could repre- 
sent a good, noninvasive marker of liver fibrosis. This is in accordance with our study where IGF-1 levels were associated with advanced stages of fibrosis. Others causes contributing to low IGF-1 in adults are malnutrition and diabetes mellitus [44] and it is worth mentioning that none of our patients were diabetic and none of the participants showed clinical evidence of protein-calorie malnutrition or signs of vitamin deficiency. IGF-1 was found to decrease serum insulin [45]. We were able to demonstrate a similar negative correlation between IGF-1 and insulin.

Our results concerning the HOMA-IR are in partial agreement with previously published data which could be due to different population studied as most Egyptian $\mathrm{HCV}$ patients carry genotype 4 [46] and also the absence of baseline HOMA-IR figures before therapy to be compared with scores taken during and after therapy.

Genotypes were found to behave differently concerning IR, steatosis, fibrosis and response to treatment. In genotype 1, IR has been associated with steatosis development and fibrosis progression [47] and SVR rate was twice in patients with HOMA $\leq 2$ compared to those with HOMA $\geq 2$ [48]. While in genotype 3, viral induced hepatic steatosis is likely to be due to direct cytopathic effect of HCV independent of IR [49]. Previous data suggest that IR at baseline has been linked to treatment failure $[2,50,51]$. Thus further studies assessing baseline and follow up score of HOMA-IR might be of great value to monitor the effect of IR on treatment outcome.

\section{Conclusions}

Patients with chronic HCV infection exhibit insulin resistance and low levels of serum IGF-1 following combined IFN/ribavirin therapy irrespective of treatment response. Low IGF-1 levels might reflect the severity of chronic liver disease in addition to an increased HOMAIR and thus can be postulated to be of pathogenic etiology in the development of IR in patients with CHC.

\section{Acknowledgements}

The authors acknowledge the efforts of professor Dr. Gamal Esmat, professor of Tropical Medicine and Head of Schistosomal Liver Unit, professor Dr. Maissa ELRaziky, professor of Tropical Medicine and Dr. Wafaa El-Akel, fellow of Tropical Medicine, Cairo University for their full cooperation and help in providing retrospective data about the recruited patients and facilitating contact with them.

\section{References}

[1] M. Romero-Gómez, M. Del Mar Viloria, R. J. Andrade, J.
Salmerón, M. Diago, C. M. Fernández-Rodríguez, R. Corpas, M. Cruz, L. Grande, L. Vázquez, P. Muñoz-De-Rueda, P. López-Serrano, A. Gila, M. L. Gutiérrez, Pérez C, A. Ruiz-Extremera, E. Suárez and J. Castillo, "Insulin Resistance Impairs Sustained Response Rate to Peginterferon plus Ribavirin in Chronic Hepatitis C Patients," Gastroenterology, Vol. 128, No. 3, 2005, pp. 636-641. doi:10.1053/j.gastro.2004.12.049

[2] F. Imazeki, O. Yokosuka, K. Fukai, T. Kanda, H. Kojima and H. Saisho, "Prevalence of Diabetes Mellitus and Insulin Resistance in Patients with Chronic Hepatitis C: Comparison with Hepatitis B Virus-Infected and Hepatitis C Virus-Cleared Patients," Liver International, Vol. 28, No. 3, 2008, pp. 355-362. doi:10.1111/j.1478-3231.2007.01630.x

[3] R. Moucari, T. Asselah, D. Cazals-Hatem, H. Voitot, N. Boyer, M. P. Ripault, R. Sobesky, M. Martinot-Peignoux, S. Maylin, M. H. Nicolas-Chanoine, V. Paradis, M. Vidaud, D. Valla, P. Bedossa and P. Marcellin, "Insulin Resistance in Chronic Hepatitis C: Association with Genotypes 1 and 4, Serum HCV RNA Level, and Liver Fibrosis," Gastroenterology, Vol. 134, No. 2, 2008, pp. 416-423. doi:10.1053/j.gastro.2007.11.010

[4] E. R. Parise and A. C. Oliveira, "Insulin Resistance in Chronic Hepatitits C," Arquivos de Gastroenterologia, Vol. 44, No. 2, 2007, pp. 178-184. doi:10.1590/S0004-28032007000200017

[5] S. A. Harrison, "Insulin Resistance among Patients with Chronic Hepatitis C: Etiology and Impact on Treatment," Clinical Gastroenterology and Hepatology, Vol. 6, No. 8, 2008, pp. 864-876. doi:10.1016/j.cgh.2008.03.024

[6] M. Y. Sheikh, J. Choi, I. Qadri, J. E. Friedman and A. J. Sanyal, "Hepatitis C Virus Infection: Molecular Pathways to Metabolic Syndrome," Hepatology, Vol. 47, No. 6, 2008, pp. 2127-2133. doi:10.1002/hep.22269

[7] L. Fartoux, A. Poujol-Robert, J. Guéchot, D. Wendum, R. Poupon and L. Serfaty, "Insulin Resistance is a Cause of Steatosis and Fibrosis Progression in Chronic Hepatitis C," Gut, Vol. 54, No. 7, 2005, pp. 1003-1008. doi:10.1136/gut.2004.050302

[8] J. M. Hui, A. Sud, G. C. Farrell, P. Bandara, K. Byth, J. G. Kench, G. W. Mccaughan and J. George, "Virus-Induced Insulin Resistance May Be a Mechanism for Fibrogenesis in Chronic Hepatitis C Virus Infection," Gastroenterology, Vol. 125, No. 6, 2003, pp. 1695-1704. doi:10.1053/j.gastro.2003.08.032

[9] J. M. Petit, J. B. Bour, C. Galland-Jos, et al., "Risk Factors for Diabetes Mellitus and Early Insulin Resistance in Chronic Hepatitis C," Journal of Hepatology, Vol. 35, No. 2, 2001, pp. 279-283. doi:10.1016/S0168-8278(01)00143-X

[10] R. D’Souza, C. A. Sabin and G. R. Foster “Insulin Resistance Plays a Significant Role in Liver Fibrosis in Chronic Hepatitis C and in the Response to Antiviral Therapy," The American Journal of Gastroenterology, Vol. 100, No. 7, 2005, pp. 1509-1515. doi:10.1111/j.1572-0241.2005.41403.x

[11] H. Poustchi, F. Negro, J. Hui, I. H. Cua, L. R. Brandt, J. 
G. Kench and J. George, "Insulin Resistance and Response to Therapy in Patients Infected with Chronic Hepatitis C Virus Genotypes 2 and 3," Journal of Hepatology, Vol. 48, No. 1, 2008, pp. 28-34. doi:10.1016/j.jhep.2007.07.026

[12] A. Picardi, U. V. Gentilucci, E. M. Zardi, D. Caccavo, T. Petitti, S. Manfrini, P. Pozzilli and A. Afeltra, "TNF-Alpha and Growth Hormone Resistance in Patients with Chronic Liver Disease," Journal of Interferon \& Cytokine Research, Vol. 23, No. 5, 2003, pp. 229-235. doi:10.1089/107999003321829944

[13] M. Coculescu, D. Niculescu, R. Lichiardopol and M. Purice, "Insulin Resistance and Insulin Secretion in NonDiabetic Acromegalic Patients," Experimental and Clinical Endocrinology \& Diabetes, Vol. 115, No. 5, 2007, pp. 308-316. doi:10.1055/s-2007-961797

[14] E. Succurro, F. Andreozzi, A. Sciaqua, M. L. Hribal, F. Perticone and G. Sesti, "Reciprocal Association of Plasma IGF-1 and Interleukin-6 Levels with Cardiometabolic Risk Factors in Nondiabetic Subjects," Diabetes Care, Vol. 31, No. 9, 2008, pp. 1886-1888. doi: $10.2337 / \mathrm{dc} 08-0553$

[15] G. Morali, A. B. Shitrit, M. Eran, S. Freier, C. Reinus and D. Braverman, "Hepatic Production of Insulin-Like Growth Factors in Normal and Diseased Liver," Hepato-Gastroenterology, Vol. 52, No, 65, 2005, pp. 1511-1515.

[16] F. C. Goetz, "A Simple Immunoassay for Insulin: Application to Human and Dog Plasma," The Journal of Clinical Endocrinology \& Metabolism, Vol. 23, No. 12, 1963, pp. 1237-1246. doi:10.1210/jcem-23-12-1237

[17] E. Bonora, G. Targher, M. Alberiche, R. C. Bonadonna, F. Saggiani, M. B. Zenere, T. Monauni and M. Muggeo, "Homeostasis Model Assessment Closely Mirrors the Glucose Clamp Technique in the Assessment of Insulin Sensitivity: Studies in Subjects with Various Degrees of Glucose Tolerance and Insulin Sensitivity," Diabetes Care, Vol. 23, No. 1, 2000, pp. 57-63. doi:10.2337/diacare.23.1.57

[18] C. A. Burtis and E. R. Ashwood, "Tietz Fundamentals of Clinical Chemistry," 4th Edition, W. B. Saunders Company, Philadelphia, 1996.

[19] E. M. Rutanen and F. Pekonen, "Assays for IGF Binding Proteins," Acta Endocrinologica (Copenhagen), Vol. 124, Supplement. 2, 1991, pp. 70-73.

[20] S. Radhakrishnan, P. Abraham, S. Raghuraman, G. T. John, P. P. Thomas and C. K. Jacob, et al., "Role of Molecular Techniques in the Detection of HBV DNA and HCV RNA among Renal Transplant Recipients in India," Indian Journal of Medical Research, Vol. 111, 2000, pp. 204-211.

[21] A. K. Panigrahi, S. K. Nanda, R. K. Dixit, S. K. Acharya, A. J. Zuckerman and S. K. Panda, "Diagnosis of Hepatitis C Virus-Associated Chronic Liver Disease in India: Comparison of HCV Antibody Assay with a Polymerase Chain Reaction for the 5' Noncoding Region," Journal of Medical Virology, Vol. 44, No. 2, 1994, pp. 176-179. doi:10.1002/jmv.1890440211

[22] P. Bedossa and T. Poynard, "An Algorithm for the Gra- ding of Activity in Chronic Hepatitis C. The METAVIR Cooperative Study Group," Hepatology, Vol. 24, No. 2, 1996, pp. 289-293. doi:10.1002/hep.510240201

[23] A. Picardi, D. D’Avola, U. V. Gentilucci, G. Galati, E. Fiori, S. Spataro and A. Afeltra, "Diabetes in Chronic Liver Disease: From Old Concepts to New Evidence," Diabetes/Metabolism Research and Reviews, Vol. 22, No. 4, 2006, pp. 274-283. doi:10.1002/dmrr.636

[24] W. P. Pimenta, M. L. Santos, N. S. Cruz, F. F. Aragon, C. R. Padovani and J. E. Gerich, "Insulin Secretion, Insulin Sensitivity, and Hepatic Insulin Extraction in First-Degree Relatives of Type 2 Diabetic Patients," Brazilian Journal of Medical and Biological Research, Vol. 36, No. 3, 2003, pp. 301-308. doi:10.1590/S0100-879X2003000300003

[25] S. Decock, C. Verslype and J. Fevery, "Hepatitis C and Insulin Resistance: Mutual Interactions. A Review," Acta Clinica Belgica, Vol. 62, No. 2, 2007, pp. 111-119.

[26] R. Narita, S. Abe, Y. Kihara, T. Akiyama, A. Tabaru and Otsuki M, "Insulin Resistance and Insulin Secretion in Chronic Hepatitis C Virus Infection," Journal of Hepatology, Vol. 41, No. 1, 2004, pp. 132-138. doi:10.1016/j.jhep.2004.03.020

[27] V. Mello, T. Cruz, G. Nuñez, M.T. Simões, F. Ney-Oliveira, H. Braga, C. Araújo, S. Cunha, M. I. Schinoni, M. Cruz and R. Parana, "Peripheral Insulin Resistance during Treatment of Chronic Hepatitis C with Peguilated Interferon plus Ribavirin," Journal of Medical Virology, Vol 78, No. 11, 2006, pp. 1406-1410. doi:10.1002/jmv.20712

[28] C. Giordanino, E. Bugianesi, A. Smedile, A. Ciancio, M. L. Abate, A. Olivero, R. Pellicano, M.Cassader, R. Gambino, S. Bo, G. Ciccone, M. Rizzetto and G. Saracco, "Incidence of Type 2 Diabetes Mellitus and Glucose Abnormalities in Patients with Chronic Hepatitis C Infection by Response to Treatment: Results of a Cohort Study," The American Journal of Gastroenterology, Vol. 103, No. 10, 2008, pp. 2481-2487. doi:10.1111/j.1572-0241.2008.02002.x

[29] M. Romero-Gómez, C. Fernandez-Rodriguez, S. Alonso, J. A. Pons, P. López-Serrano, M. L. Gutiérrez, C. Pérez, R. Temiño, P. García, L. Grande and M. Diago. "Sustained Response in Chronic Hepatitis C Reduces the Risk to Develop Impaired Fasting Glucose and/or Diabetes Type 2," Journal of Hepatology, Vol. 44, Supplement. 2, 2006, p. 204.

[30] A. J. Sanyal, N. Chand, K. Comar and F. Mirshahi, "Hyperinsulinemia Blocks the Inhibition of Hepatitis C Virus (HCV) Replication by Interferon: A Potential Mechanism for Failure of Interferon Therapy in Subjects with HCV and Nonalcoholic Fatty Liver Disease," Hepatology, Vol 40, Supplement. 1, 2004, p. 179.

[31] H. Noto and P. Raskin, "Hepatitis C Infection and Diabetes," Journal of Diabetes and Its Complications, Vol. 20, No. 2, 2006, pp. 13-20. doi:10.1016/j.jdiacomp.2006.01.001

[32] T. C. Schreuder, H. C. Gelderblom, C. J. Weegink, D. Hamann, H. W. Reesink, J. H. Devries, J. B. Hoekstra and P. L. Jansen, "High Incidence of Type 1 Diabetes 
Mellitus during or Shortly after Treatment with Pegylated Interferon Alpha for Chronic Hepatitis C Virus Infection," Liver International, Vol. 28, No. 1, 2008, pp. 39-46. doi:10.1111/j.1478-3231.2007.01610.x

[33] I. J. Hickman, A. D. Clouston, G. A. Macdonald, D. M. Purdie, J. B. Prins, S. Ash, J. R. Jonsson and E. E. Powell, "Effect of Weight Reduction on Liver Histology and Biochemistry in Patients with Chronic Hepatitis C," Gut, Vol. 51, No. 1, 2002, pp. 89-94. doi:10.1136/gut.51.1.89

[34] M. Romero-Gómez, V. M. Castellano-Megias, L. Grande, J. A. Irles, M. Cruz, M. C. Nogales, J. C. Alcón and A. Robles, "Serum Leptin Levels Correlate with Hepatic Steatosis in Chronic Hepatitis C," The American Journal of Gastroenterology, Vol. 98, No. 5, 2003, pp. 1135-1141. doi:10.1016/S0002-9270(03)00185-0

[35] A. Lecube, C. Hernández, J. Genescà, J. I. Esteban, R. Jardí and R. Simó, 'High Prevalence of Glucose Abnormalities in Patients with Hepatitis C Virus Infection: A Multivariate Analysis Considering the Liver Injury," Diabetes Care, Vol. 27, No. 5, 2004, pp. 1171-1175. doi:10.2337/diacare.27.5.1171

[36] V. Ratziu, M. Munteanu, F. Charlotte, L. Bonyhay and T. Poynard, "Fibrogenic Impact of High Serum Glucose in Chronic Hepatitis C," Journal of Hepatology, Vol. 39, No. 6, 2003, pp. 1049-1055. doi:10.1016/S0168-8278(03)00456-2

[37] V. Paradis, D. Dargere, M. Vidaud, et al., "Expression of Connective Tissue Growth Factor in Experimental Rat and Human Liver Fibrosis," Hepatology, Vol. 30, No. 4, 1999, pp. 968-976. doi:10.1002/hep.510300425

[38] V. Paradis, G. Perlemuter, F. Bonvoust, et al., "High Glucose and Hyperinsulinemia Stimulate Connective Tissue Growth Factor Expression: A Potential Mechanism Involved in Progression to Fibrosis in Nonalcoholic Steatohepatitis," Hepatology, Vol. 34, No. 4, 2001, pp. 738-744. doi:10.1053/jhep.2001.28055

[39] I. H. Cua, J. M. Hui, J. G. Kench and J. George, "Genotype-Specific Interactions of Insulin Resistance, Steatosis, and Fibrosis in Chronic Hepatitis C," Hepatology, Vol. 48, No. 3, 2008, pp. 723-731. doi:10.1002/hep.22392

[40] T. Asselah, N. Boyer, M. C. Guimont, D. Cazals-Hatem, F. Tubach, K. Nahon, et al., "Liver Fibrosis is not Associated with Steatosis but with Necroinflammation in French Patients with Chronic Hepatitis C," Gut, Vol. 52, No. 11, 2003, pp. 1638-1643. doi:10.1136/gut.52.11.1638

[41] G. Leandro, A. Mangia, J. Hui, P. Fabris, L. Rubbia-Brandt, G. Colloredo, et al., "The Relationship between Hepatic Steatosis, Inflammation and Fibrosis in Chronic Hepatitis C: A Meta-Analysis of Individual Patient Data," Gastroenterology, Vol. 130, No. 6, 2006, pp. 1636-1642.

\section{Abbreviations}

Insulin resistance (IR), chronic hepatitis $\mathrm{C}(\mathrm{CHC})$, hepatitis $\mathrm{C}$ virus (HCV), growth hormone $(\mathrm{GH})$, insulin resistance doi:10.1053/j.gastro.2006.03.014

[42] U. Plöckinger, D. Krüger, A. Bergk, V. Weich, B. Wiedenmann and T. Berg, "Growth Hormone Deficiency Common in Hepatitis C Patients, but Improves with Interferon-Based Treatment," The American Journal of Gastroenterology, Vol. 102, No. 12, 2007, pp. 2724-2731.

[43] J. B. Li, C. Y. Wang, J. W. Chen, Z. Q. Feng and H. T. $\mathrm{Ma}$, "Expression of Liver Insulin-Like Growth Factor 1 Gene and Its Serum Level in Patients with Diabetes," World Journal of Gastroenterology, Vol. 10, No. 2, 2004, pp. 255-259.

[44] A. Y. Kwan and M. L. Hartman, "IGF-I Measurements in the Diagnosis of Adult Growth Hormone Deficiency," Pituitary, Vol. 10, No. 2, 2007, pp. 151-157. doi:10.1007/s11102-007-0028-8

[45] A. C. Moses, "Insulin Resistance and Type 2 Diabetes Mellitus: Is There a Therapeutic Role for IGF-1?" Endocrine Development, Vol. 9, 2005, pp. 121-134. doi: $10.1159 / 000085762$

[46] M. Abdel-Hamid, M. El-Daly, V. Molnegren, S. El-Kafrawy, S. Abdel-Latif, G. Esmat, G. T. Strickland, C. Loffredo, J. Albert and A. Widell, "Genetic Diversity in Hepatitis C Virus in Egypt and Possible Association with Hepatocellular Carcinoma," Journal of General Virology, Vol. 88, No. 5, 2007, pp. 1526-1531. doi:10.1099/vir.0.82626-0

[47] M. Romero-Gómez, "Hepatitis C and Insulin Resistance: Steatosis, Fibrosis and Non-Response," Revista Española de Enfermedades Digestivas, Vol. 98, No. 8, 2006, pp. 605-615.

[48] M. Romero-Gómez, "Insulin Resistance and Hepatitis C," World Journal of Gastroenterology, Vol. 12, No. 44, 2006, pp. 7075-7080.

[49] S. Bondini and Z. M. Younossi, "Non-Alcoholic Fatty Liver Disease and Hepatitis C Infection," Minerva Gastroenterol Dietol, Vol. 52, No. 2, 2006, pp. 135-143.

[50] S. B. Missiha, M. Ostrowski and E. J. Heathcote, "Disease Progression in Chronic Hepatitis C: Modifiable and Nonmodifiable Factors," Gastroenterology, Vol. 134, No. 6, 2008, pp. 1699-1714. doi:10.1053/i.gastro.2008.02.069

[51] V. G. Bain, K. D. Kaita, P. Marotta, E. M. Yoshida, M. G. Swain, R. J. Bailey, K. Patel, P. W. Cronin, E. Pulkstenis, J. G. McHutchison and G. M. Subramanian, "Safety and Antiviral Activity of Albinterferon Alfa-2b Dosed Every Four Weeks in Genotype 2/3 Chronic Hepatitis C Patients," Clinical Gastroenterology and Hepatology, Vol. 6, No. 6, 2008, pp. 701-706.

doi:10.1016/j.cgh.2008.02.056

index (HOMA-IR: homeostasis model of assessment), body mass index (BMI), tumor necrosis factor $\alpha$ (TNF- $\alpha$ ), insulin-like growth factor 1 (IGF-1), diabetes mellitus (DM), interferon (IFN), radioimmunoassay (RIA). 